\title{
Caracterização bioquímica de fitases produzidas por fungos isolados na região do Alto Paranaíba em Minas Gerais
}

\author{
Biochemical characterization of phytases produced by fungi \\ from the Alto Paranaíba region in Minas Gerais
}

Marília Crivelari da Cunha ${ }^{[a]}$, Paulo Sérgio Monteiro[ ${ }^{[b]}$, Fabrícia Queiroz Mendes ${ }^{[c]}$

[a] Bacharel em Ciências de Alimentos, Instituto de Ciências Agrárias, Universidade Federal de Viçosa (UFV), Rio Paranaíba, MG - Brasil, e-mail: mari_crivelari@yahoo.com.br

[b] Bacharel em Ciência e Tecnologia de Laticínios, Doutor em Bioquímica Agrícola, Professor adjunto do Instituto de Ciências Agrárias, Universidade Federal de Viçosa (UFV), Rio Paranaíba, MG - Brasil, e-mail: psmonteiro@ufv.br

[c] Engenheira de Alimentos, Doutora em Bioquímica Agrícola, Professora adjunta do Instituto de Ciências Agrárias, Universidade Federal de Viçosa (UFV), Rio Paranaíba, MG - Brasil, e-mail: fabricia.mendes@ufv.br

\section{Resumo}

No Brasil, a adição de fitases em ração animal tem sido usada para minimizar os efeitos antinutricionais do ácido fítico, além de diminuir os impactos ambientais e a adição de fósforo na ração. Este estudo teve como objetivo avaliar a produção de fitases e caracterizar, bioquimicamente, as enzimas produzidas por fungos isolados na região do Alto Paranaíba, no estado de Minas Gerais. Foram utilizados quatro isolados de Rhizopus sp., obtidos a partir de amostras de amendoim e dois isolados de Aspergillus niger, um isolado de Trichoderma sp., um isolado de Xylaria sp. e um isolado de Fusarium sp., obtidos no banco de culturas do laboratório de Microbiologia da Universidade Federal de Viçosa (UFV), campus Rio Paranaíba. Os isolados de Rhizopus sp., Thichoderma sp. e Fusarium sp. não apresentaram atividade enzimática significativa, enquanto os isolados de A. niger e Xylaria sp., por apresentarem atividade enzimática significativa, foram selecionados para a etapa de caracterização bioquímica. Na fermentação no estado líquido, um dos isolados de $A$. niger apresentou maior atividade enzimática (0,89 U.mL-1) em 216 h, enquanto na fermentação no estado sólido, o isolado de Xylaria sp. apresentou maior atividade enzimática (2,88 U.g-1) em 264 h. A fitase de Xylaria sp. apresentou pH ótimo igual a 2,5, temperatura ótima de $45^{\circ} \mathrm{C}$ e manteve $91 \%$ de atividade residual, após ser mantida a $50{ }^{\circ} \mathrm{C}$ durante 15 min., enquanto a fitase de $A$. niger apresentou pH ótimo igual a 3, temperatura ótima de $60^{\circ} \mathrm{C}$ e manteve $68 \%$ de atividade residual, após ser mantida a $70{ }^{\circ} \mathrm{C}$ durante $15 \mathrm{~min}$. Os resultados indicam que as enzimas apresentam potencial para aplicação industrial.

Palavras-chave: Fosfatase. Fitato. Ração animal. 


\section{Abstract}

In Brazil, phytase is added to animal feed to minimize antinutritional effects of phytic acid, as well as to reduce environmental impact and addition of phosphorus to food. This study aimed to evaluate the production of phytase and to biochemically characterize enzymes produced by fungi from the Alto Paranaíba region in the state of Minas Gerais. Four isolates of Rhizopus sp. were obtained from peanut samples, and two isolates of Aspergillus niger, one isolate of Trichoderma sp., one isolate of Xylaria sp., and one isolate of Fusarium sp. were obtained from the culture bank of the microbiology laboratory of the Federal University of Viçosa (UFV) at Rio Paranaíba. Isolates of Rhizopus sp., Trichoderma sp., and Fusarium sp. did not demonstrate significant enzyme activity, while those of A. niger and Xylaria sp. had significant enzymatic activity and were selected for further biochemical characterization. During liquid fermentation, an A. niger isolate had the highest enzyme activity (0.89 U.mL-1) at $216 \mathrm{~h}$, while during solid-state fermentation, the Xylaria sp. isolate showed the highest enzyme activity (2.88 U.g-1) at $264 \mathrm{~h}$. The phytase produced by the Xylaria sp. had optimal $p H$ and temperature of 2.5 and $45{ }^{\circ} \mathrm{C}$, respectively, and maintained $91 \%$ residual activity after incubation at $50^{\circ} \mathrm{C}$ for $15 \mathrm{~min}$. The A. niger phytase had optimum $\mathrm{pH}$ and temperature of 3 and $60^{\circ} \mathrm{C}$, respectively, and maintained $68 \%$ residual activity after incubation at $70{ }^{\circ} \mathrm{C}$ for $15 \mathrm{~min}$. These results indicate that the isolated phytases have potential for industrial application.

Keywords: Phosphatase. Phytate. Animal feed.

\section{Introdução}

O Brasil é considerado um dos maiores produtores de ração animal da América Latina, ocupando a terceira posição no ranking mundial, atrás dos Estados Unidos e China. De acordo com o Sindicato Nacional da Indústria de Alimentação Animal, em 2011, foram produzidos 64,5 milhões de toneladas de rações e mais de 2,35 milhões de toneladas de sal mineral, que representou um crescimento de 5,2\% em relação ao ano anterior (Sindirações, 2012).

Devido à ocorrência da encefalopatia espongiforme bovina (BSE), conhecida como mal da vaca louca, vários países, como o Brasil e a Comunidade Europeia, proibiram a utilização de produtos de origem animal na alimentação de ruminantes e monogástricos, os quais foram substituídos por dietas compostas, principalmente, de milho e farelo de soja (Sá, 2005).

0 ácido fítico (ácido mio-inositol 1,2,3,4,5,6-hexafosfórico), também denominado de fitato, é a principal fonte de fósforo em sementes de cereais e leguminosas, onde se apresenta complexado a vários cátions. No entanto, o fósforo fítico não é absorvido por animais monogástricos, sendo excretado nos resíduos animais, contribuindo para o aumento da poluição ambiental (Zhang et al., 2010; Zuo et al., 2010). A não absorção de fósforo na forma de ácido fítico ocorre devido aos animais monogástricos, incluindo o homem, não apresentarem ou apresentarem em quantidades insuficientes, as enzimas que catalisam a hidrólise de fitato no trato gastrointestinal (Vats e Banerjee, 2004). Além disso, a capacidade de formar complexos insolúveis com cátions tais como $\mathrm{Ca}^{2+}$, $\mathrm{Mg}^{2+}, \mathrm{Zn}^{2+}$, e com proteínas, faz com que o fitato seja considerado um constituinte antinutricional, pois reduz a biodisponibilidade desses compostos (Bohn et al., 2008).

A produção de enzimas é uma área da biotecnologia em expansão mundial, a qual movimenta bilhões de dólares anualmente (Viniegra-González et al., 2003). Os processos utilizados para produção de enzimas podem ocorrer por meio da fermentação submersa (FSM), processo mais utilizado em escala industrial, ou por meio da fermentação no estado sólido (FES) (Castro e Pereira Jr., 2010), onde diversos subprodutos agroindustriais têm sido usados como substratos para a produção de enzimas, sobretudo por serem de baixo custo e apresentarem elevada disponibilidade (Martins et al., 2007).

A adição de enzimas em ração animal é crescente no mercado mundial e tem sido explorada para aumentar o valor nutricional de dietas animais (Pariza e Cook, 2010).

As fitases (mio-inositol (1,2,3,4,5,6) hexaquisfosfato fosfohidrolase) são fosfatases 
com a capacidade de liberar, in vitro, pelo menos um grupo fosfato por meio da hidrólise do fitato, diminuindo a concentração de inositol fosfato e potenciais minerais quelados (Bohn et al., 2008). Desta forma, o tratamento de dietas animais com fitases aumenta a disponibilidade de fósforo inorgânico, melhorando o valor nutricional dos alimentos, e também contribui para a redução da poluição ambiental, causada pelo excesso de fósforo excretado nos resíduos animais (Nahm, 2002).

As fitases podem ser obtidas por processos biotecnológicos a partir de fontes de origem animal e vegetal. No entanto, as fitases de origem microbiana representam a forma mais promissora de produção destas enzimas, as quais têm sido utilizadas em rações animais. Apesar da capacidade de produção de bactérias e leveduras, os fungos são mais utilizados devido às suas fitases apresentarem maior estabilidade térmica, maior estabilidade em faixas mais amplas de $\mathrm{pH}$, elevada especificidade catalítica e maior resistência à proteólise, quando comparadas com as fitases de plantas (Casey e Walsh, 2003; Kim et al., 2006; Selle e Ravindran, 2007; Bohn et al., 2008),

o Brasil, embora apresente potencial para produção de enzimas, importa a maior parte das enzimas utilizadas no país. Esse potencial é evidenciado pela grande diversidade biológica, ainda pouco explorada, para obtenção de novos micro-organismos produtores de enzimas e pela abundância de resíduos agrícolas, que constituem em substratos de baixo custo para as fermentações (Bon et al., 2008). Neste contexto, este estudo teve como objetivo avaliar a produção de fitases e caracterizar, bioquimicamente, as enzimas produzidas por fungos isolados na região do Alto Paranaíba (MG).

\section{Materiais e métodos}

\section{Micro-organismos}

Os fungos do gênero Xylaria sp., Trichoderma sp., Fusarium sp. e Aspergillus niger foram obtidos no Laboratório de Microbiologia da Universidade Federal de Viçosa, campus Rio Paranaíba. Os isolados de Rhizopus sp. foram obtidos a partir de amostras de amendoim (Arachis hypogea L.), adquiridas no comércio local da cidade de Rio Paranaíba (MG).

Para o isolamento dos fungos a partir de amendoim, foi utilizado o método do papel de filtro (Blotter-test), conforme descrito pela International Seed Testing Associaton (ISTA, 1976). Foram utilizadas caixas plásticas, previamente higienizadas com solução de etanol a 70\%. No fundo das caixas, foram colocadas duas folhas de papel de filtro esterilizadas e umedecidas com água destilada estéril. Posteriormente, foram introduzidos os grãos de amendoim sobre as folhas de papel, sendo as caixas incubadas em estufa tipo BOD, a $28^{\circ} \mathrm{C}$ durante 7 dias. Após o período de incubação, para a obtenção de culturas puras, as colônias desenvolvidas foram transferidas para placas de Petri contendo ágar batata dextrose (BDA), previamente esterilizadas a $121{ }^{\circ} \mathrm{C}$ por $15 \mathrm{~min}$. Em seguida, as placas foram incubadas em estufa a $28{ }^{\circ} \mathrm{C}$ durante 7 dias.

\section{Crescimento e inoculação dos fungos}

0 crescimento dos fungos Xylaria sp., Trichoderma sp., Fusarium sp., A. niger e Rhizopus sp. foi realizado em placas de Petri contendo meio BDA, previamente esterilizadas a $121{ }^{\circ} \mathrm{C}$ por 15 min., incubadas a $28^{\circ} \mathrm{C}$ durante 7 dias.

Para a obtenção do inóculo, após a incubação, as placas contendo os fungos A. niger e Rhizopus sp., foram adicionadas de solução de $0,1 \%$ Tween 20 . A superfície das placas foi raspada com o auxílio de uma alça de platina e a suspensão de esporos obtida foi filtrada em gaze estéril. Uma alíquota da suspensão foi utilizada para a determinação da concentração de esporos em câmara de Neubauer e, com base nesta concentração, foi calculado o volume de inóculo necessário para que a concentração final de esporos no meio de cultivo líquido fosse igual a $10^{7}$ esporos/mL. Os fungos Xylaria sp., Trichoderma sp. e Fusarium sp. foram inoculados por meio da transferência de 5 a 6 discos (8 $\mathrm{mm}$ de diâmetro) do meio BDA contendo o inóculo para os meios de cultura.

\section{Fermentação no estado líquido}

Os meios de cultura líquido e sólido foram preparados de acordo com Gunashree e Venkateswaran (2008), com modificações. 
0 meio líquido foi composto por infusão de batata $(200 \mathrm{~g} / \mathrm{L})$; sacarose $(10 \mathrm{~g} / \mathrm{L})$; peptona $(5$ $\mathrm{g} / \mathrm{L})$; Tween 20 (2,5 mL/L) e CaCl2 (0,10 g/L), com pH ajustado para 5,5 e esterilizado a $121^{\circ} \mathrm{C}$ durante 15 min. Foram utilizados frascos Erlenmeyer de 125 $\mathrm{mL}$, contendo $25 \mathrm{~mL}$ de meio de cultura, que, após a inoculação, foram incubados em mesa agitadora orbital (Marconi, modelo MA 376), sob temperatura ambiente e agitação de 180 rpm. Alíquotas do meio foram coletadas em intervalos predeterminados e filtradas em algodão para obtenção do extrato bruto utilizado para a determinação da atividade enzimática. As fermentações e as análises de atividade enzimática foram realizadas em triplicata.

\section{Fermentação no estado sólido}

A fermentação no estado sólido foi realizada em frascos Erlenmeyer de 1L, contendo $50 \mathrm{~g}$ de farelo de trigo, 0,5 g de sacarose e 0,25 g de peptona, com umidade ajustada para $60 \%$. Todo o conteúdo dos frascos foi homogeneizado e autoclavado por 40 min. a $121{ }^{\circ} \mathrm{C}$, e na sequência os mesmos foram incubados a $30^{\circ} \mathrm{C}$ na posição horizontal estática. As análises de atividade enzimática foram realizadas após o crescimento dos fungos sob a superfície do meio sólido. Após o crescimento celular e produção da enzima, foi adicionado ao frasco fermentador de $1 \mathrm{~L}, 250 \mathrm{~mL}$ de tampão acetato $0,2 \mathrm{M}$ em pH 4,5 a temperatura de $4{ }^{\circ} \mathrm{C}$. $\mathrm{O}$ meio de cultura foi homogeneizado com bastão de vidro e levado para agitação em mesa agitadora orbital (Marconi, modelo MA 376) a $200 \mathrm{rpm}$ por $20 \mathrm{~min}$. e o extrato bruto foi filtrado em papel Whatman $\mathrm{n}^{\circ}$. 1 . As fermentações foram realizadas em duplicata e as análises de atividade enzimática em triplicata.

\section{Determinação da atividade enzimática}

A atividade enzimática foi determinada no sobrenadante das culturas, medindo o fosfato inorgânico liberado (Taussky e Shorr, 1953), utilizando-se $600 \mu \mathrm{L}$ do substrato fitato de sódio 1,5 mM, em tampão acetato de sódio, em pH 5,0 e 150 $\mu \mathrm{L}$ de extrato enzimático. A reação foi conduzida em banho-maria a $50{ }^{\circ} \mathrm{C}$ durante $30 \mathrm{~min}$., sendo paralisada pela adição de $250 \mu \mathrm{L}$ da solução de ácido tricloroacético $10 \%$. Foram adicionados aos tubos de reação, $1000 \mu \mathrm{L}$ do reativo colorimétrico, que consiste de uma solução de ácido sulfúrico 5 M, molibidato de amônio e sulfato ferroso. As leituras de absorbância foram realizadas em espectrofotômetro em $700 \mathrm{~nm}$ (Spectrum, modelo SP-2000UV) e os valores obtidos foram correlacionados com uma curva padrão confeccionada com $\mathrm{KH}_{2} \mathrm{PO}_{4}$. Todas as análises de atividade enzimática foram realizadas em triplicata, considerando como sendo uma unidade enzimática, a quantidade de enzima necessária para liberação de $1 \mu \mathrm{mol}$ de fosfato inorgânico por min., sob as condições de ensaio.

\section{Efeito do pH na atividade enzimática}

Para a determinação do pH ótimo das enzimas, o ensaio enzimático foi realizado em diferentes valores de $\mathrm{pH}$ ( 2 a 8), utilizando as seguintes soluções tampão: glicina-HCl 0,2 M (pH 2,0 - 3,5), acetato de sódio 0,2 M (pH 4,0 - 5,5), MES 0,2 M (pH 6,0 - 6,5) e Tris-HCl 0,2 M (pH 7,0 - 8,0). Após a realização dos ensaios enzimáticos, foi determinada a atividade enzimática relativa, considerando a maior atividade como sendo $100 \%$.

\section{Efeito da temperatura na atividade enzimática}

Para a determinação da temperatura ótima das enzimas, os ensaios enzimáticos foram realizados na faixa de temperatura entre $20^{\circ} \mathrm{C}$ a $80{ }^{\circ} \mathrm{C}$. Após a realização dos ensaios enzimáticos, foi determinada a atividade enzimática relativa, considerando a maior atividade como sendo $100 \%$.

\section{Estabilidade térmica da fitase}

A estabilidade térmica das fitases foi determinada incubando-se os extratos enzimáticos em diferentes temperaturas, na faixa de $50^{\circ} \mathrm{C}$ a $80^{\circ} \mathrm{C}$ durante $2 \mathrm{~h} \mathrm{e}$ 5 h. Após esses períodos de pré-incubação, alíquotas dos extratos foram coletadas, sendo realizado o ensaio enzimático de cada alíquota, em triplicata. A atividade enzimática relativa foi determinada pela correlação com a atividade da enzima não submetida aos tratamentos, a qual foi considerada como sendo $100 \%$ de atividade. Os valores de tempo de meia vida $(\mathrm{t} 1 / 2)$, tempo necessário para o decaimento de $50 \%$ da atividade inicial das enzimas, para cada temperatura, foi calculado pela curva de atividade 
relativa (\%) em função do tempo de incubação, utilizando o programa Curve Expert 1.3.

\section{Resultados}

Fundamentado nas características morfológicas macroscópicas, foram obtidos, a partir dos grãos de amendoim, 4 isolados de Rhizopus sp. No presente trabalho, também foram utilizados 2 isolados de A. niger, 2 isolados de Trichoderma sp., 1 isolado de Xylaria sp. e 1 isolado de Fusarium sp., os quais foram obtidos no laboratório de Microbiologia da Universidade Federal de Viçosa, campus de Rio Paranaíba.

Os isolados de Rhizopus sp., Trichoderma sp. e Fusarium sp. não apresentaram atividade enzimática significativa em meio líquido, os quais não foram avaliados, posteriormente, em meio sólido. Um dos isolados de $A$. niger apresentou maior atividade enzimática $\left(0,89 \mathrm{U} \cdot \mathrm{mL}^{-1}\right)$ após $216 \mathrm{~h}$ de cultivo em meio líquido e não apresentou atividade significativa na fermentação em estado sólido. No entanto, o isolado de Xylaria sp. apresentou atividade enzimática de 2,88 U.g ${ }^{-1}$ após $264 \mathrm{~h}$ de fermentação em estado sólido e não apresentou resultado significativo em meio líquido.

Conforme pode ser observado na Figura 1, o $\mathrm{pH}$ ótimo para a fitase de A. niger foi igual a 3 , porém foi observado um segundo pico de atividade em $\mathrm{pH} 5$, o qual apresentou $46 \%$ da atividade enzimática observada em $\mathrm{pH}$ 3,0. A fitase de Xylaria sp. apresentou pH ótimo igual a 2,5, a qual também apresentou um segundo pico de atividade enzimática em $\mathrm{pH} 5$, com $57 \%$ da atividade enzimática observada no $\mathrm{pH}$ de máxima atividade. A fitase de $A$. niger não apresentou atividade enzimática a partir de $\mathrm{pH} 5,5$, enquanto que a fitase de Xylaria sp. apresentou uma redução da atividade enzimática até $\mathrm{pH} 7,0$, onde apresentou $9 \%$ de atividade enzimática relativa.

Na avaliação da influência da temperatura na atividade enzimática, pode ser observado que a fitase de $A$. niger apresentou temperatura ótima de $60{ }^{\circ} \mathrm{C}$, enquanto que a enzima de Xylaria sp. apresentou temperatura ótima de $45{ }^{\circ} \mathrm{C}$ (Figura 2).

Quanto à estabilidade das enzimas à temperatura, a fitase de Xylaria sp. apresentou, a $50{ }^{\circ} \mathrm{C}, 91 \%$ da atividade residual após $15 \mathrm{~min}$. e tempo de meia vida ( $\mathrm{t} 1 / 2)$ de $22,3 \mathrm{~min}$. Na temperatura de $60^{\circ} \mathrm{C}$, a enzima manteve $33 \%$ de atividade residual após 15 min. e apresentou $\mathrm{t} 1 / 2$ de 8,3 min (Figura 3).

A fitase de A. niger apresentou, a $70{ }^{\circ} \mathrm{C}, 68 \%$ da atividade residual após $15 \mathrm{~min}$. e t $1 / 2$ de $33,9 \mathrm{~min}$. Na temperatura de $80{ }^{\circ} \mathrm{C}$, o valor de $\mathrm{t} 1 / 2$ foi igual a 13,4 min (Figura 4).

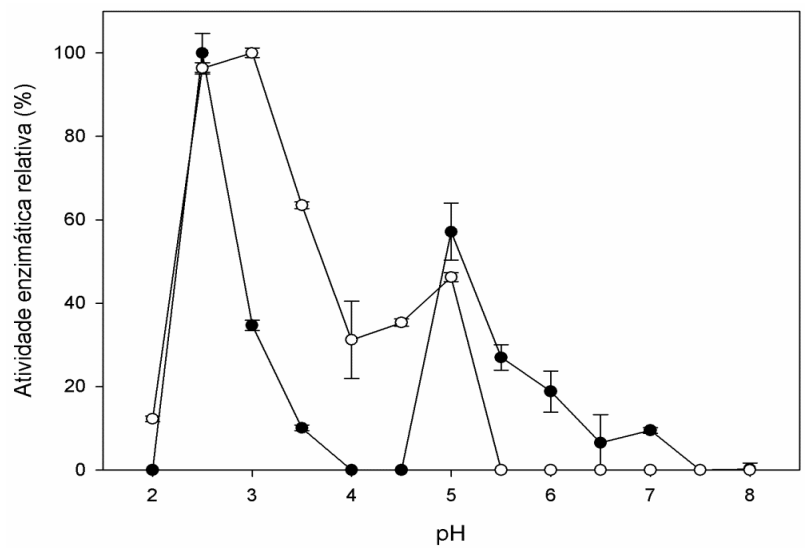

Figura 1 - Efeito do $\mathrm{pH}$ na atividade de fitase de Aspergillus niger (o) e Xylaria sp. (•).

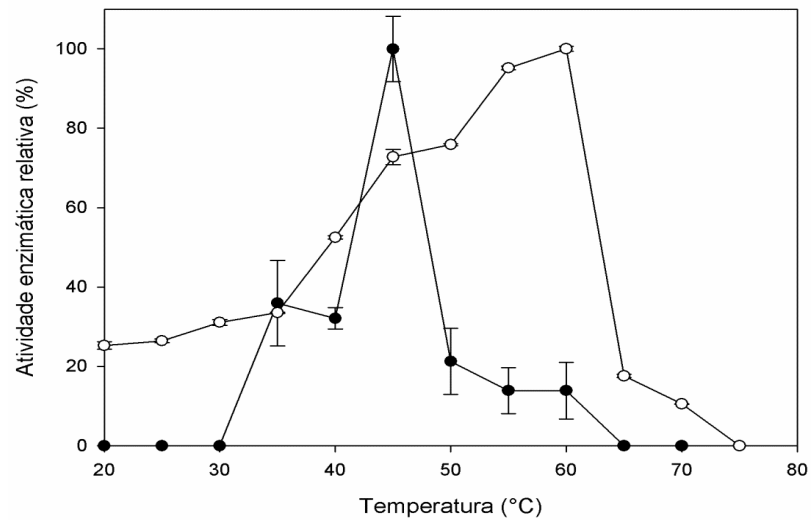

Figura 2 - Efeito da temperatura na atividade de fitase de Aspergillus niger (o) e Xylaria sp. (•).

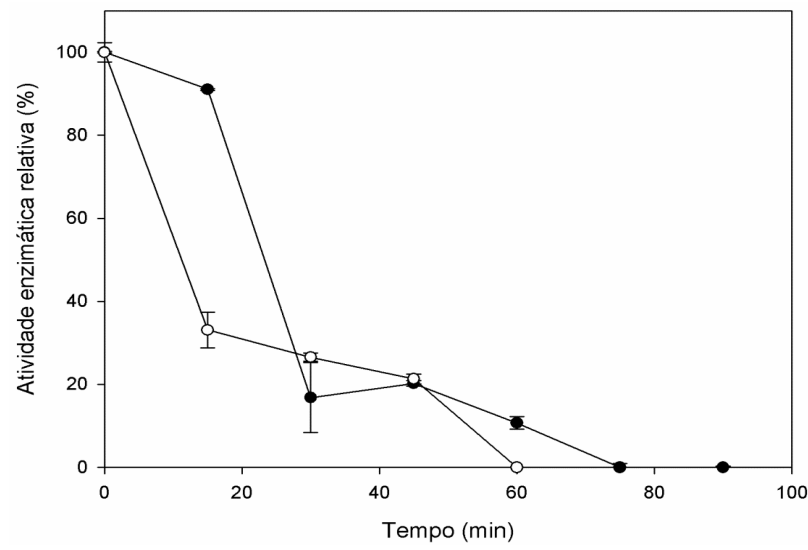

Figura 3 - Estabilidade térmica da fitase de Xylaria sp. a $50{ }^{\circ} \mathrm{C}(\bullet)$ e $60^{\circ} \mathrm{C}(\mathrm{o})$. 


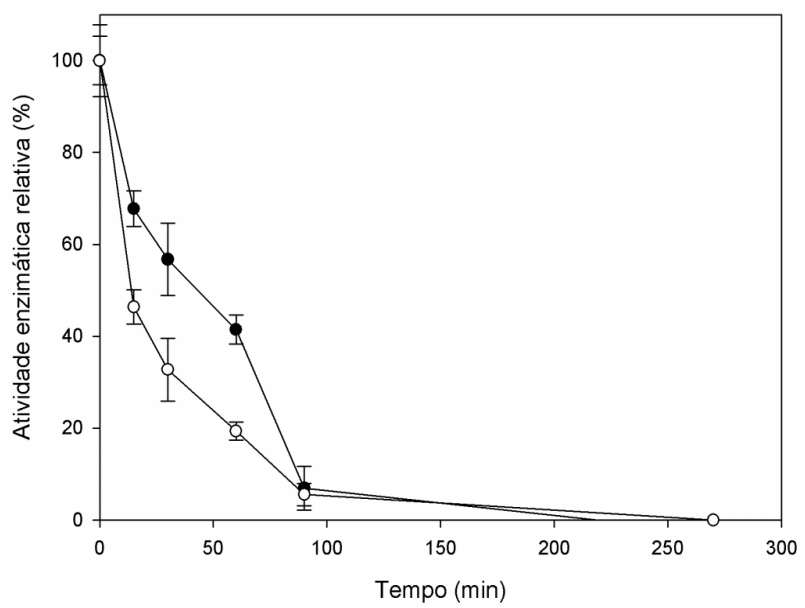

Figura 4 - Estabilidade térmica da fitase de Aspergilus niger a $70{ }^{\circ} \mathrm{C}(\bullet)$ e $80^{\circ} \mathrm{C}(\mathrm{o})$.

\section{Discussão}

Os isolados de $A$. niger e Xylaria sp., que apresentaram atividade enzimática significativa nas condições avaliadas, foram selecionados para a etapa de caracterização bioquímica das fitases produzidas. A ausência de atividade de fitases pelo isolado de $A$. niger em meio sólido ocorreu, provavelmente, em função da presença de fósforo no substrato, que pode ter influenciado na inibição da síntese da enzima (Gunashree e Venkateswaran, 2008).

Os resultados encontrados para o isolado de Rhizopus sp. foram diferentes dos encontrados por Marlida et al. (2010), que avaliaram a produção de fitases por Rhizoctonia sp. e Fusarium verticillioides, em meio líquido, e obtiveram, como melhores resultados, atividade enzimática de $0,78 \mathrm{U}_{\mathrm{mL}} \mathrm{m}^{-1} \mathrm{e}$ $0,46 \mathrm{U} \cdot \mathrm{mL}^{-1}$, respectivamente.

As diferenças encontradas na atividade de fitases podem ter ocorrido em função da produção enzimática ser influenciada por uma série de fatores tais como, tipo de micro-organismo, idade da cultura, composição do meio, entre outros. Deste modo, não existe um meio de cultura definido para a produção de fitases por diferentes fontes de micro-organismos, especialmente os fungos, que apresentam necessidades particulares e substratos específicos para a obtenção de uma produção otimizada das enzimas (Bhavsar et al., 2011).

Os resultados obtidos neste trabalho na avaliação da influência do pH sobre a atividade enzimática foram semelhantes aos resultados encontrados por Casey e Walsh (2003), que obtiveram pH ótimo igual a 5 para a fitase de A. niger ATCC 9142 e também semelhantes aos resultados encontrados para fitases de A. niger FS3 com pH ótimo igual a 5,5 (Spier et al., 2010). Marlida et al. (2010), avaliaram a fitase de Fusarium verticillioides, a qual apresentou atividade enzimática na faixa de $\mathrm{pH}$ entre 2,5 e 7,0, com pH ótimo igual a 5. Segundo Casey e Walsh (2004), algumas fitases apresentam dois picos de atividade em diferentes valores de $\mathrm{pH}$, devido a diferenças de distribuição de cargas no sítio de ligação com o substrato.

Os resultados de $\mathrm{pH}$ ótimo encontrados para as fitases de A. niger e Xylaria sp. sugerem que as enzimas possam apresentar estabilidade em $\mathrm{pH}$ ácido, podendo atuar a nível estomacal de animais. Outra característica importante observada pela fitase de Xylaria sp., é a possível estabilidade da enzima no intestino dos animais, uma vez que foi observada atividade enzimática em $\mathrm{pH} 7,0$. A estabilidade enzimática em diferentes faixas de $\mathrm{pH}$ é importante para que a enzima possa ser efetiva no trato gastrointestinal dos animais (Casey e Walsh, 2004).

A temperatura ótima obtida para a fitase de $A$. niger avaliada foi similar aos resultados encontrados por Marlida et al. (2010), que encontraram temperatura ótima igual a $50{ }^{\circ} \mathrm{C}$ para as fitases de Rhizoctonia sp. e Fusarium verticillioides. A temperatura ótima da maioria das fitases fúngicas, geralmente, encontra-se na faixa de $50{ }^{\circ} \mathrm{C}$ a $60{ }^{\circ} \mathrm{C}$ (Pandey et al., 2001; Konietzny e Greiner, 2002).

De acordo com os resultados obtidos, a fitase de A. niger apresentou maior termoestabilidade em relação à fitase de Xylaria sp., que, por sua vez, apresentou similaridade com a estabilidade térmica da fitase de Fusarium verticillioides, avaliada por Marlida et al. (2010), que apresentou $100 \%$ da atividade enzimática residual após $30 \mathrm{~min}$. a $50{ }^{\circ} \mathrm{C}$, enquanto que nas temperaturas de $60{ }^{\circ} \mathrm{C}$ e $80{ }^{\circ} \mathrm{C}$, a enzima manteve $70 \%$ e $10 \%$ da atividade inicial, respectivamente. Em um trabalho semelhante, Casey e Walsh (2003), compararam a fitase de A. niger ATCC 9142 com fitases comerciais e observaram que a enzima manteve $22 \%$ de atividade residual após 3 min. a $80{ }^{\circ} \mathrm{C}$, enquanto que as enzimas comerciais mantiveram, no máximo, $18 \%$ de atividade residual. 
As enzimas com maior termoestabilidade apresentam vantagens para aplicação industrial, uma vez que o risco de contaminação por microorganismos mesófilos é significativamente reduzido em processos biotecnológicos onde se utilizam elevadas temperaturas (Gomes et al., 2007). Além disso, o isolamento e caracterização de enzimas com esta propriedade é um pré-requisito importante para o sucesso da aplicação de enzimas na alimentação animal, uma vez que, nos processos industriais de fabricação de rações, são utilizadas temperaturas elevadas, variando de $60^{\circ} \mathrm{C}$ a $90^{\circ} \mathrm{C}$ (Tomschy et al., 2002). No entanto, existe a possibilidade de utilização das enzimas que não apresentam essa característica, as quais podem ser incorporadas às dietas em uma etapa anterior ao processo de peletização de rações, evitando a perda da atividade enzimática pelo calor (Cao et al., 2007).

\section{Conclusão}

As fitases produzidas pelos isolados de Xylaria sp. e Aspergillus niger apresentam potencial para aplicação industrial, principalmente a fitase de $A$. niger, a qual, além de ter apresentado atividade enzimática em $\mathrm{pH}$ ácido, apresentou maior termoestabilidade. A fitase de Xylaria sp., mesmo apresentando menor termoestabilidade, apresentou características relevantes, como atividade enzimática em $\mathrm{pH}$ ácido e em $\mathrm{pH}$ neutro. No entanto, para um possível aproveitamento das enzimas a nível industrial, ainda são necessários novos estudos, bem como, aumentar o rendimento da produção das mesmas.

\section{Referências}

Bhavsar K, Kumar VR, Khire JM. High level phytase production by Aspergillus niger NCIM 563 in solid state culture: response surface optimization, upscaling, and its partial characterization. Journal of Industrial Microbiology \& Biotechnology. 2011; 38(9):1407-1417. doi:10.1007/ s10295-010-0926-z.
Bohn L, Meyer AS, Rasmussen SK. Phytate: impact on environment and human nutrition. A challenge for molecular breeding. Journal of Zhejiang University Science B. 2008; 9(3):165191. doi:10.1631/jzus.B0710640.

Bon EPS, Ferrara MA, Corvo ML. Enzimas em Biotecnologia: produção, aplicações e mercado. Rio de Janeiro: Editora Interciência, 2008.

Cao L, Wang W, Yang C, Yang Y, Diana J, Yakupitiyage A, Luo Z, Li D. Application of microbial phytase in fish feed. Enzyme and Microbial Technology. 2007; 40(4):497-507. doi:10.1016/j.enzmictec.2007.01.007.

Casey A, Walsh G. Purification and characterization of extracellular phytase from Aspergillus niger ATCC 9142. Bioresource Technology. 2003; 86(2):183-188. doi:10.1016/ S0960-8524(02)00145-1.

Casey A, Walsh G. Identification and characterization of a phytase of potential commercial interest. Journal of Biotechnology. 2004; 110(3):313-322. doi:10.1016/j. jbiotec.2004.03.001.

Castro AM, Pereira Jr N. Produção, propriedades e aplicação de celulases na hidrólise de resíduos agroindustriais. Química Nova. 2010; 33(1):181188. doi:10.1590/S0100-40422010000100031.

Gomes E, Guez MAU, Martin N, Silva R. Enzimas termoestáveis: fontes, produção e aplicação industrial. Química Nova. 2007; 30(1):136-145. doi:10.1590/S0100-40422007000100025.

Gunashree B, Venkateswaran G. Effect of different cultural conditions for phytase production by Aspergillus niger CFR 335 in submerged and solid-state fermentations. Journal of Industrial Microbiology \& Biotechnology. 2008; 35(12):1587-1596. doi:10.1007/ s10295-008-0402-1.

International Seed Testing Association - ISTA. Seed health testing. Seed Science and Technology. 1976; 4:3-49. 
Kim T, Mullaney EJ, Porres JM, Roneker KR, Crowe S, Rice S, Ko T, Ullah AHJ, Daly CB, Welch R, Lei $\mathrm{XG}$. Shifting the $\mathrm{pH}$ profile of Aspergillus niger PhyA phytase to match the stomach $\mathrm{pH}$ enhances its effectiveness as an animal feed additive. Applied and Environmental Microbiology. 2006; 72(6):4397-4403. doi:10.1128/AEM.02612-05.

Konietzny U, Greiner R. Molecular and catalytic properties of phytate-degrading enzymes (phytases). International Journal of Food and Technology. 2002; 37(7):791-812. doi:10.1046/j.1365-2621.2002.00617.x.

Marlida Y, Delfita R, Adnadi P, Ciptaan G. Isolation, characterization and production of phytase from endophytic fungus its application for feed. Pakistan Journal of Nutrition. 2010; 9(5):471474. doi:10.3923/pjn.2010.471.474.

Martins ES, Silva D, Leite RSR, Gomes E, Silva R. Purification and characterization of polygalacturonase produced by thermophilic Thermoascus aurantiacus CBMAI-756 in submerged fermentation. Antonie van Leeuwenhoek International. 2007; 91(3):291299. doi:10.1007/s10482-006-9114-6.

Nahm KH. Efficient feed nutrient utilization to reduce pollutants in poultry and swine manure. Critical Reviews in Environmental Science and Technology. 2002; 32(1):1-16. doi:10.1080/10643380290813435.

Pandey A, Szakacs G, Soccol CR, RodriguezLeon JA, Soccol VT. Production purification and properties of microbial phytases. Bioresource Technology. 2001; 77(3): 203-214. doi:10.1016/ S0960-8524(00)00139-5.

Pariza MW, Cook M. Determining the safety of enzymes used in animal feed. Regulatory Toxicology and Pharmacology. 2010; 56(3):332342. doi:10.1016/j.yrtph.2009.10.005.

Sá LM. Ingredientes alternativos na alimentação de suínos - Economia e segurança. 2005. Disponível em: <http://www.polinutri.com.br/ upload/artigo/170.pdf>. Acesso em: 28 abr. 2014.

Selle PH, Ravindran V. Microbial phytase in poultry nutrition. Animal Feed Science and Technology. 2007; 135(1-2):1-41. doi:10.1016/j. anifeedsci.2006.06.010

Sindirações. Indústria de alimentação animal sente os efeitos do alto custo dos insumos. Setor de Alimentação Animal. Dezembro/2012 (Boletim Informativo do Setor). Disponível em: $<$ http://sindiracoes.org.br/boletim-informativodo-setor-dezembro-2012>. Acesso em: 28 jan. 2015.

Spier MR, Fendrich R, Almeida PC, Noseda M, Greiner R, Konietzny U, Woiciechowski AL, Soccol VT, Soccol CR. Phytase produced on citric byproducts: purification and characterization. World Journal of Microbiology and Biotechnology. 2010; 27(2):267-274. doi:10.1007/ s11274-010-0455-y.

Taussky HH, Shorr E. A microcolorimetric method for the determination of inorganic phosphorus. The Journal of Biological Chemistry. 1953; 202(2):675-685.

Tomschy A, Brugger R, Lehmann M, Svendsen A, Vogel K, Kostrewa D, Lassen SF, Burger D, Kronenberger A, van Loon AP, Pasamontes L, Wyss M Engineering of phytase for improved activity at low pH. Applied and Environmental Microbiology. 2002; 68(4):1907-1913.

Vats P, Banerjee UC. Production studies and catalytic properties of phytases ( m y o i nos i tolh exakis phos phat e phosphohydrolases): an overview. Enzyme Microbial Technology. 2004; 35(1):3-14. doi:10.1016/j.enzmictec.2004.03.010.

Viniegra-González G, Favela-Torres E, Aguilar CN, Rómero-Gomes SJ, Díaz-Godínez G, Augur C. Advantages of fungal enzyme production in solid state over liquid fermentation system. Biochemical Engineering Journal. 2003; 13(2-3):157-167. doi:10.1016/S1369-703X(02)00128-6. 
Zhang GQ, Dong XF, Wang ZH, Zhang Q, Wang HX, Tong JM. Purification, characterization, and cloning of a novel phytase with low $\mathrm{pH}$ optimum and strong proteolysis resistance from Aspergillus ficuum NTG-23. Bioresource Technology. 2010; 101(11):4125-4131. doi:10.1016/j.biortech.2010.01.001.
Zuo R, Chang J, Yin Q, Chen L, Chen Q, Yang $X$, Zheng Q, Ren G, Feng H. Phytase gene expression in Lactobacillus and analysis of its biochemical characteristics. Microbiological Research. 2010; 165(4):329-335. doi:10.1016/j. micres.2009.06.001.

Recebido em: 17/05/2015

Received in: 05/17/2015

Aprovado em: 14/10/2015

Approved in: 10/14/2015 